\title{
LA ORACIÓN, PRIORIDAD PASTORAL
}

DOI: https://doi.org/10.52039/seminarios.v58i204.308

Elías Yanes Álvarez*

La vida cristiana no se reduce a la oración, pero la oración es una dimensión importante de la vida cristiana. Para el sacerdote es una necesidad vital. Dice el papa Benedicto XVI: «Tenemos que conocer a Jesús de manera cada vez más personal, escuchándole, viviendo junto a él, estando con él. Escucharlo, en la lectio divina, es decir, leyendo la Sagrada Escritura, pero no de una manera académica, sino espiritual; de este modo aprendemos a encontrar a Jesús presente que nos habla» ${ }^{1}$.

Este encuentro con Jesús es posible si leemos y meditamos la Escritura en un clima de oración, de diálogo humilde con Dios. «La lectura de la Sagrada Escritura es oración, tiene que ser oración, tiene que surgir de la oración y llevar a la oración», dice el Papa. Y añade: «El tiempo que dedicamos a esto es realmente tiempo de actividad pastoral, de una actividad auténticamente pastoral» (Homilía en la Misa crismal de 2006).

«El tiempo que se pasa en encuentro directo con Dios en la oración se puede describir correctamente como la prioridad pastoral por excelencia: es la respiración del alma sin la cual el sacerdote sigue siendo necesariamente 'desalentado', privado del 'oxígeno' del optimismo y del gozo, que necesita para dejarse enviar, día a día, como trabajador en la mies del Señor» (Benedicto XVI, 14-IX2006). Esta consideración también es válida para cualquier agente de pastoral (persona consagrada o seglar).

En la lectura creyente y eclesial de la Sagrada Escritura, en un clima de oración, Dios nos habla «aquí y ahora» a «cada uno», y nos otorga su Espíritu Santo para que podamos escuchar su voz con fe y amor obediente (cf. Verbum Domini 51, 80, 81, 86).

Todos los cristianos estamos llamados por Dios a la perfección en el amor a Dios y al prójimo, a imitación de Cristo: «Todos los cristianos, de cualquier estado o condición, están llamados a la plenitud de la vida cristiana y a la perfección del amor... Lo harán siguiendo las huellas de Cristo, haciéndose conformes a su imagen y siendo obedientes en todo a la voluntad del Padre» (LG 40-41). En la Iglesia no existe una vocación a la mediocridad espiritual.

* Mons. Elías Yanes es arzobispo emérito de Zaragoza.

1. Benedicto XVI, Verbum Domini, nn. 86-87: lectio, meditatio, oratio, contemplatio. 
Nuestra norma de conducta: «No anteponer nada a Cristo, porque tampoco Él antepuso nada a nosotros» (san Cipriano, san Benito, Benedicto XVI) ${ }^{2}$. Sin oración no hay amistad con Cristo y con el Padre, ni docilidad al Espíritu. Afirma san Pablo: «Nadie puede decir: 'Jesús es Señor' sino por el Espíritu Santo» (1 Cor 12, 3). Sin la acción del Espíritu en nosotros y en los demás, nuestra actividad pastoral es ineficaz. Hemos de implorar incesantemente su presencia y poner en él, no en nosotros, nuestra confianza.

\section{ORACIÓN Y AMOR AL PRÓJIMO}

Sin oración tampoco es posible la caridad fraterna. La verdadera caridad fraterna consiste en participar de los sentimientos de Cristo respecto a nuestro prójimo (cf. Flp 2, 1-5ss). Amar a Dios significa amar a nuestros prójimos como Dios les ama en Cristo-Jesús. Y para esto hemos de suplicar incesantemente el don del Espíritu que derrame en nuestro corazones amor de Dios (cf. Rom 5, 5; Gal $5,6.12-26)$. Que haga de nosotros sembradores de caridad: "Os exhortamos a que ... animéis a los pusilánimes, sostengáis a los débiles y seáis pacientes con todos. Mirad que nadie devuelva a otro mal por mal, antes bien, procurad siempre el bien mutuo y el de todos. Estad siempre alegres. Orad constantemente. En todo dad gracias, pues esto es lo que Dios, en Cristo Jesús, quiere de vosotros» (1 Tes 5, 14-18; cf. 1 Jn 2, 11; 3, 23; 4, 13-16.20.21; Ef 1, 3-14; 2, 1-10; 3, 14-21).

El himno a la caridad de 1 Cor 13 , 1ss se refiere a la caridad fraterna, pero implícitamente también se refiere al amor a Dios, en conexión con la fe y la esperanza (1 Cor 13,13$)$. «Si no tengo caridad (= amor), soy como bronce que suena o címbalo que retiñe... si no tengo caridad, nada soy» (v. 1-2). La invitación de Jesús al joven rico, «Ven y sígueme», es la nueva forma concreta de amor a Dios y al prójimo (cf. Mt 19, 21; 5, 48; Lc 6, 36). No seremos capaces de seguir a Cristo sólo con nuestras fuerzas ${ }^{3}$. Necesitamos la gracia del Espíritu, que hemos de pedir: «Padre, en nombre de Jesús, dame tu Espíritu» ${ }^{4}$.

La fe viva en el trato de amistad con Jesús nos hace ver a Jesús presente en el prójimo necesitado (Mt 25, 31-46). Con este criterio seremos juzgados por Dios. Mi prójimo es un tesoro que Dios me confía: «Los hermanos son en realidad como un tesoro que pertenece a Dios y que Dios ha colocado bajo tu cuidado» ${ }^{5}$.

Cuando se deteriora nuestra relación con el prójimo, también se deteriora nuestro trato de amistad con Jesús en la oración: «Faltar a la caridad es como

2. Cipriano, Obras de san Cipriano, BAC, Madrid 1964, 335, VI; 342; san Benito, Su vida y su regla, BAC, Madrid 1968, 710; Benedicto XVI, Audiencia general, 25 de abril de 2005.

3. Juan Pablo II, Veritatis Splendor, n. 17-26.

4. A. Albuquerque, En el corazón de la reforma. «Recuerdos espirituales del Bto. Pedro Fabro», Mensajero, Bilbao 2000, 129, n. 57.

5. Gregorio de Nisa. Cf. Liturgia de las Horas IV, 260. 
herir a Dios en la pupila de su ojo» ${ }^{6}$. «Quien ama con su amor quiere a los hombres para Dios y no para sí» ${ }^{7}$. «No aceptéis como verdad nada que carezca de amor. Y no aceptéis como amor nada que carezca de verdad. El uno sin la otra se convierte en una mentira destructora» ${ }^{8}$.

«El amor es el signo de la presencia del Espíritu Santo. Las ideas o las palabras que carecen de amor, aunque parezcan sofisticadas o sagaces, no pueden ser 'del Espíritu'» ${ }^{9}$. No separemos nuestra oración de la reconciliación con el prójimo: «Perdona nuestras ofensas como también nosotros perdonamos a los que nos ofenden» (Mt 6, 12).

Santa Teresa de Jesús nos exhorta a la vigilancia: «¡Oh! Que quedan unos gusanos que no se dan a entender, hasta que, como el que royó la yedra de Jonás, nos han roído las virtudes, como un amor propio, una propia estimación, un juzgar los prójimos, aunque sea en pocas cosas, una falta de caridad con ellos, no los queriendo como a nosotros mismos; que, aunque arrastrando cumplimos con la obligación para no ser pecado, no llegamos con mucho a lo que ha de ser para estar del todo unidas con la voluntad de Dios» $(5 \mathrm{M} \mathrm{3,} \mathrm{6;} \mathrm{cf.} \mathrm{Jonás} \mathrm{4,} \mathrm{6-7})^{10}$.

\section{LA ORACIÓN, DIÁLOGO DE AMISTAD}

Para santa Teresa de Jesús la oración es diálogo de amistad: «Que no es otra cosa oración mental, a mi parecer, sino tratar de amistad, estando muchas veces tratando a solas con quien sabemos nos ama» $(\mathrm{V} 8,5)^{11}$.

¿Qué es orar realmente? Orar no es lo que nosotros hacemos, sino lo que acontece en nosotros y en el corazón de Dios cuando nos ponemos delante de él. «Como sucede con la amistad, ambas experiencias tienen mucho más de don recibido que de producto ganado y trabajado. También como en todo don, es crucial el dónde y el cómo lo recibimos» ${ }^{12}$.

En la oración no se trata sólo de «hablar yo», sino sobre todo de «escuchar» a Dios que me ama y me habla en el silencio. Para ello lo más importante es atender a Dios Padre, a Jesucristo... a la persona a la que trato. Lo fundamental no

6. Pio de Pietrelcina, Pensieri e parole, Paoline, Roma 1999, 35.

7. Edith Stein (Santa Teresa Benedicta de la Cruz), Obras selectas, Monte Carmelo, Burgos 1998, 383.

8. Juan Pablo II, Homilía en la misa de canonización de Santa Teresa Benedicta de la Cruz, 11 de octubre de 1998.

9. Benedicto XVI, en Sidney, 19 de julio de 2008.

10. Siglas de las obras de Santa Teresa de Jesús: $V=$ Vida; $C=$ Camino de perfección, autógrafo de Valladolid; 5M3, 6 = Moradas quintas, capítulo 3, párrafo 6 .

11. Cf. M. Herráiz García, La oración, historia de amistad, Editorial de Espiritualidad, Madrid 1985, ${ }^{6} 2003$; T. Álvarez-J. Castellano, Teresa de Jesús, enséñanos a orar, Monte Carmelo, Burgos ${ }^{3} 1982$.

12. A. Guillén, Agradecer tanto bien recibido, Instituto Teológico de Vida Religiosa, Vitoria 2006, 11-12. 
son los «asuntos», sino la relación entre amigos. En esta amistad he de buscar sobre todo complacer a Dios, no satisfacer mis gustos o el éxito de mis planes. "No está la cosa en pensar mucho, sino en amar mucho» (Santa Teresa de Jesús, $4 M 1,7)$. «No os pido más de que le miréis» (4M 26, 3-5; 25, 3; 28, 2ss). Orar es descubrirme amado por Dios, es tomar a Dios por amigo (cf. Lc 11,5) y desear, con su gracia, unir mi voluntad a la suya en todo; es concentración en el amor que Dios nos otorga. Es reconocer con fe viva, su presencia envolvente, penetrante, su presencia de amor entrañable y misericordioso: es el Padre de nuestro Señor Jesucristo, que en Cristo me ama desde toda la eternidad. Dios Padre quiere hacerme vivir en el amor con que Él y su Hijo Jesucristo se aman entre sí en el Espíritu Santo. «Quizás no sabemos qué es amar-decía santa Teresa de Jesús a sus monjas- y no me espantaré mucho; porque no está la cosa en el mayor gusto, sino en la mayor determinación de desear contentar en todo a Dios y procurar, en cuanto pudiéremos, no le ofender, y rogarle que vaya siempre adelante la honra y gloria de su Hijo y el aumento de la Iglesia Católica» $(4 \mathrm{M} 1,7)$.

Escuchar a Dios: «En realidad en la vida del hombre los elementos válidos, que se convierten en vida son pocos y relativamente simples. El hombre necesita poseerlos 'con el corazón'» ${ }^{13}$. El lenguaje de Dios es muy simple, sencillo y unitario. Afecta a todo el ser del hombre. Dice muy pocas cosas, pero fundamentales. Nos habla de su amor por la persona concreta. Y en el mismo amor se comunica, entrega y orienta» ${ }^{14}$.

Permanezcamos en el amor de Jesús: «Como el Padre me ha amado, así os he amado yo a vosotros. Permaneced en mi amor. Si guardáis mis mandamientos, permaneceréis en mi amor, como yo he guardado los mandamientos de mi Padre, y permanezco en su amor» (Jn 15, 9-10).

La vida de oración es inseparable de la abnegación personal para buscar sólo lo que le agrada a Dios. Dice san Ignacio de Loyola: «porque piense cada uno que tanto aprovechará en todas cosas espirituales quanto saliere de su propio amor, querer e interesse» (Ejercicios Espirituales [= Ej] n. 189).

\section{ORACIÓN Y HUMILDAD: ANDAR EN VERDAD}

Santa Teresa de Jesús recibió una luz especial para comprender la verdadera humildad, sin la cual no hay auténtico amor a Dios y al prójimo: «Una vez estaba yo considerando por qué razón era nuestro Señor tan amigo de esta virtud de la humildad, y púsoseme delante... esto: que es porque Dios es la suma Verdad, y la humildad es andar en verdad, que lo es muy grande no tener cosa buena en nosotros, sino la miseria y ser nada; y quien esto no entiende, anda

13. Cf. Arzubialde, Ejercicios Espirituales de san Ignacio, Mensajero, $2^{\mathrm{a}}$ ed., p. 215.

14. Ibid., 209. 
en mentira. A quien más lo entiende agrada más a la suma Verdad, porque anda en ella» (6M 10, 6-7). «Díjome (el Señor): ... ¿sabes qué es amarme con verdad? Entender que todo es mentira lo que no es agradable a mí» (V 40,3). «Entendí el gran bien que hay en no hacer cosa que no sea para llegarnos más a Dios. Y así entendí qué cosa es andar un alma en verdad delante de la misma Verdad» (V 40, 1-3).

«Esta verdad que digo se me dio a entender, es en sí misma y es sin principio ni fin, $y$ todas las demás verdades dependen de esta verdad, como todos los demás amores de este amor, y todas las demás grandezas de esta grandeza, aunque esto va dicho oscuro para la claridad con que a mí el Señor quiso me diese a entender. ¡Y cómo se parece el poder de esta Majestad, pues en tan breve tiempo deja tan gran ganancia y tales cosas imprimidas en el alma!» ( $\mathrm{V} \mathrm{40,4).}$ Ideas semejantes en san Ignacio de Loyola, Contemplación para alcanzar amor (Ej 237). Añade la Santa Doctora: «Estando una vez en oración, se me representó muy en breve... cómo se ven en Dios todas las cosas y cómo las tiene todas en sí. Saber escribir esto, yo no lo sé, mas quedó muy imprimido en mi alma, y es una de las grandes mercedes que el Señor me ha hecho y de las que más me han hecho confundir y avergonzar, acordándome de los pecados que he hecho» (V 40, 9ss), «porque es en el mismo Dios -digo, estando dentro en Él- hacemos grandes maldades» (6M 10, 2-3).

San Ignacio de Loyola, en la Contemplación para alcanzar amor: «El segundo mirar cómo Dios habita en las criaturas, en los elementos dando ser, en las plantas vegetando, en los animales sensando, en los hombres dando entender; y así en mí seyendo criado a la similitud e imagen de su divina majestad; otro tanto reflectiendo en mí mismo, por el modo que está dicho... El tercero considerar cómo Dios trabaja y labora por mí en todas cosas criadas sobre la haz de la tierra, id est, habet se ad modum laborantis. Así como en los cielos, elementos, plantas, fructos, ganados, etc. Dando ser, conservando, vegetando y sensando, etc. Después reflectir en mí mismo. El quarto: mirar cómo todos los bienes y dones descienden de arriba, así como la mi medida potencia de la suma y infinita de arriba, y así justicia, bondad, piedad, misericordia, etc. Así como del sol descienden los rayos, de la fuente las aguas etc. Después acabar reflictiendo en mí mismo según está dicho» (Ej 235-236).

Advierte santa Teresa que «la humildad verdadera... no viene con alboroto, ni desasosiega el alma ni la oscurece ni da sequedad; antes la regala, y es todo al revés: con quietud, con suavidad, con luz» ( $\mathrm{V} 30,9)$. «No puedo yo entender cómo haya ni pueda haber humildad sin amor, ni amor sin humildad; ni es posible estar estas dos virtudes sin gran desasimiento de todo lo creado» $(6 \mathrm{M} 10,7)$.

La humildad no es encogimiento: Dios «es amigo de ánimas animosas, como vayan con humildad y ninguna confianza en sí» $(\mathrm{V} 13,2)$. «Pongamos los ojos en Cristo y allí aprenderemos la verdadera humildad y ennoblecerse ha el entendimiento... y no hará el propio conocimiento ratero y cobarde» (1M 2, 10-12). 
«Cuanto el hombre es ante Dios, tanto es y no más» (san Francisco de Asís) ${ }^{15}$. «Bendecid a los que os persiguen... No te dejes vencer por el mal, antes bien, vence el mal con el bien» (Rom 12, 14-16.21).

\section{SIEMPRE AGRADECIDOS A DIOS}

Quizás hay etapas o aspectos de nuestra persona que no aceptamos. Esta falta de aceptación dificulta nuestro trato con Dios. El descontento interior, la amargura de corazón, la decepción por no haber podido satisfacer nuestros sueños, deseos o afectos desordenados, en cuanto implican olvido del amor de Dios o resentimiento contra Dios, se oponen a la intimidad filial con Él. Es como quejarnos ante Dios de que nos da poco. He de suplicar a Dios «que nunca la amargura sea en mi vida más fuerte que el amor» (Himno de Laudes, lunes II).

Hemos de dar gracias a Dios, en lo posible, con holgura y espontaneidad, con satisfacción filial, por lo que Dios hace por nosotros (1 Tes 5, 16-18). En cada instante de mi vida, en cada instante de la humanidad, en cada instante del universo, Dios Padre, por medio de Jesucristo, nos está creando con amor, destinándolo todo a la plenitud de la gloria en Cristo Jesús. Orar es descansar en Dios. Es maravillarnos de su misericordia con nosotros. Incluso nuestras culpas hemos de verlas a la luz del amor del Padre que nos ofrece el perdón por medio de su Hijo clavado en la cruz. Oramos porque creemos que Dios nos escucha y nos ama: «Pedid y se os dará; buscad y hallaréis; llamad y se os abrirá» (Mt 7, 7 par). No es posible vivir agradecido a Dios y no ser feliz. Dios nos quiere felices: «No estéis tristes, pues el gozo en el Señor es vuestra fortaleza» (Neh $8,10)$. Si pensamos en el pasado, el presente o el futuro, sea para dar gracias a Dios: «Sabemos que en todas las cosas interviene Dios para bien de los que le aman: de aquellos que han sido llamados según su designio. Pues a los que de antemano conoció, también los destinó a reproducir la imagen de su Hijo, para que fuera él el primogénito entre muchos hermanos» (Rom 8, 28-29). Orar es consentir que Cristo me mire y me ame tal como soy.

«Sea el Señor tu delicia y te dará lo que pide tu corazón» (Sal $36=37$ ). Amamos a Dios cuando nos sentimos en todo felices con Él. «Bienaventurada el alma que no puede concebir gozo alguno sin Dios»; «el mayor acto de amor que podemos hacer para con Dios es sentirnos, en todo, felices con Él» ${ }^{16}$. La humildad verdadera es inseparable de la acción de gracias permanente. Todo lo que somos y lo que tenemos, menos el pecado, lo recibimos constantemente de Dios, por medio de Jesucristo: «por quien concedes al mundo todos los bienes» (Plegaria eucarística III y IV), «Por Cristo, Señor nuestro, por quien sigues crean-

15. San Francisco de Asís, Escritos... Avisos espirituales, BAC, Madrid 1978, 83.

16. Hausherr, Oración de vida, vida de oración, Mensajero, Bilbao 1967, 395, 119. 
do todos los bienes, los santificas, los llenas de vida, los bendices y los repartes entre nosotros» (Plegaria eucarística I). Mi prójimo, en todo lo que tiene de positivo, es un don para mí (cf. Juan Pablo II, Novo millennio ineunte, n. 43). «Dios nuestro Señor obrando se manifiesta, como de quien todo bien pensar, hablar y obrar procede, tomándoos por instrumento en su mayor servicio, alabanza y gloria» (san Ignacio de Loyola) ${ }^{17}$.

Cristo, Señor y Juez de la historia, aparecerá revestido de poder y de gloria: «El mismo Señor que se nos mostrará entonces lleno de gloria, viene ahora a nuestro encuentro en cada hombre y en cada acontecimiento, para que lo recibamos con fe y por el amor demos testimonio de la espera dichosa de su reino» (Prefacio III de Adviento).

\section{LA AMISTAD CON DIOS EN TODA NUESTRA VIDA}

La oración nos lleva a vivir para Jesús, en unión con Él, en su presencia, tratando de complacerle en todo. Nuestra vida de cada día ha de ser, por obra del Espíritu, ofrenda permanente que se une a la de Cristo en la Eucaristía: que «os ofrezcáis a vosotros mismos como un sacrificio vivo, santo, agradable a Dios: tal será vuestro culto espiritual. Y no os acomodéis al mundo presente, antes bien transformaos mediante la renovación de vuestra mente, de forma que podáis distinguir cuál es la voluntad de Dios: lo bueno, lo agradable, lo perfecto» (Rom 12, 1-2), «la mente de Cristo» (1 Cor 2, 16). «He aquí una buena regla de conducta: No hacer sino aquello que uno puede ofrecer al Buen Dios» ${ }^{18}$. Evangelizar es transmitir a los demás lo que hemos contemplado en la oración: «contemplata aliis tradere ${ }^{19}$. El evangelizador, si quiere hacer llegar a los demás el don de la salvación, ha de orar sin cesar, o como dice Tomás de Celano de san Francisco de Asís: Francisco «hecho todo él no ya sólo orante, sino oración » ${ }^{20}$. San Pablo es ante todo un hombre de oración continua; oraba día y noche ${ }^{21}$.

María nos enseña a contemplar con amor y humildad a Jesús, a escucharle y guardar sus palabras en el corazón (cf. Lc 2, 19; 2, 51). Ella recibió con gozo la palabra de Dios (Lc 1, 45-46ss; 8,$21 ; 11,28)$. «No hay fruto de la gracia en la historia de la salvación que no tenga como instrumento necesario la mediación de nuestra Señora» ${ }^{22}$. María es modelo de la maternidad de la Iglesia y del amor «maternal» de los evangelizadores (LG 65; cf. 1 Tes 2, 7).

17. N. Martínez-Gayol, Gloria de Dios en Ignacio de Loyola, Mensajero, Bilbao 2005, 200.

18. B. Nodet, Jean-Marie Bapt. Vianney, Curé d'Ars, Pensées, Desclée de Brouwer, Bilbao $1986,75$.

19. Tomás de Aquino, STh III, q. 40, a 1 ad 2.

20. Francisco de Asís, Obras completas. Vida segunda, de Tomás de Celano, BAC, Madrid $1978,285,95$.

21. Cf. 1 Tes 1,$2 ; 3,10 ; 5,17$; Rom 8, 27, notas en la Biblia de Jerusalén.

22. Benedicto XVI, 11 de mayo de 2007, Brasil. 
Santa Teresa de Jesús nos habla de la necesidad de una firme decisión para comenzar y proseguir el camino de la oración: «Digo que importa mucho, y el todo, una muy determinada determinación de no parar hasta llegar a ella, venga lo que viniere, suceda lo que sucediere, trabájese lo que se trabajare, murmure quien murmurare, siquiera llegue allá, siquiera se muera en el camino o no tenga corazón para los trabajos que hay en él, siquiera se hunda el mundo» $(C 21,2)$.

\section{BUSCAR LA PRESENCIA DE DIOS EN TODAS LAS COSAS}

San Ignacio de Loyola escribe la siguiente recomendación a los estudiantes de Portugal: «Se pueden ejercitar en buscar la presencia de Dios en todas las cosas, como en el conversar con alguno, andar, ver, gustar, oír, entender, y en todo lo que hiciéremos, pues es verdad que está su divina Majestad por presencia, potencia y esencia en todas las cosas. Y esta manera de meditar, hallando a nuestro Señor en todas las cosas, es más fácil que no levantarnos a las cosas divinas más abstractas, haciéndonos con trabajo a ellas presente, y causará este buen ejercicio, disponiéndonos, grandes visitaciones del Señor, aunque sea en breve oración» ${ }^{23}$.

Santa Teresa de Jesús se expresa en el mismo sentido: «Ya sabéis que Dios está en todas partes... está (el Padre eterno) tan cerca que nos oirá. No ha menester alas para ir a buscarle, sino ponerse en soledad y mirarle dentro de sí y no extrañarse de tan buen huésped; sino con gran humildad hablarle como a padre, pedirle como a padre, contarle sus trabajos, pedirle remedio para ellos, entendiendo que no es digna de ser su hija».

«Concluyo con que quien lo quisiere adquirir-pues como digo está en nuestra mano-, no se canse de acostumbrarse a lo que queda dicho (C 28, 2ss), que es señorearse poco a poco de sí mismo, no se perdiendo en balde; sino ganarse a sí para sí, que es aprovecharse de sus sentidos para lo interior. Si hablare, procure acordarse de que hay con quien hable dentro de sí misma. Si oyere, acordarse de que ha de oír a quien más cerca le habla. En fin, traer cuenta que puede, si quiere, nunca se apartar de tan buena compañía, y pesarle cuando mucho tiempo ha dejado solo a su Padre, que está necesitada de él. Si pudiere muchas veces al día; si no, sea pocas. Como lo acostumbrare, saldrá con ganancia, o presto o más tarde. Después que se lo dé el Señor, no lo trocaría por ningún tesoro».

«Pues nada se deprende sin un poco de trabajo, por amor de Dios, hermanas, que deis por bien empleado el cuidado que en esto gastareis. Y yo sé, si le tenéis, en un año y quizá en medio, saldréis con ello, con el favor de Dios» (C 28-29).

23. Carta al P. Antonio Brandao, junio de 1551, en Obras completas de san Ignacio de Loyola, BAC, Madrid 1952, 790. 
En este mismo sentido escribía la beata Isabel de la Trinidad (1880-1906): «Hay que tomar conciencia de que Dios está en lo más íntimo de nosotros e ir a todas partes en su compañía. Entonces nunca seremos superficiales, ni siquiera cuando hacemos las cosas más ordinarias, pues no vivimos de esas cosas, sino que estamos por encima de ellas» "2 . "Vivamos con Dios como con un amigo. Avivemos nuestra fe para unirnos a Él en todo lo que hagamos. Así se hacen los santos. Llevamos el cielo dentro de nosotros, pues el mismo Dios que saca a los bienaventurados con la luz de la visión se entrega a nosotros por la fe y el misterio. ¡Es el mismo Dios! Creo que he encontrado mi cielo en la tierra, pues el cielo es Dios y Dios es mi alma. El día en que comprendí esto, todo se iluminó en mi interior, y querría contar muy bajito este secreto a todos los que amo para que también ellos se unan a Dios a través de todas las cosas y se haga realidad esta oración de Cristo: '¡Padre, que sean completamente uno!' (Jn 17, 23)» (C 122; 15 de junio de 1902) $)^{25}$.

\section{CONTEMPLATIVO EN LA ACCIÓN}

Cuenta el P. Nadal: «Recibió el P. Ignacio de Dios singular gracia para contemplar libremente toda la Santísima Trinidad y descansar en ese misterio. Porque unas veces era arrastrado por la gracia de la contemplación de toda la Trinidad y era impelido hacia ella y con ella se unía de todo corazón con grandes sentimientos de devoción y gusto espiritual. Contemplaba ya al Padre, ya al Hijo, ya al Espíritu Santo. La gracia de esta contemplación la recibió con mucha frecuencia siempre, pero de un modo excepcional en los últimos años de su peregrinación terrena. No sólo concibió este modo selectísimo de oración-grande privilegio-, sino además en todas sus obras, acciones y conversaciones sentía la presencia de Dios y el gusto de las cosas espirituales como si estuviera en contemplación, siendo contemplativo en la acción (= in actione contemplativus), lo que solía expresar diciendo que había que buscar a Dios en todas las cosas» ${ }^{26}$. "Y sean exhortados a menudo a buscar en todas las cosas a Dios nuestro Señor, apartando, quanto es posible, de sí el amor de todas las criaturas, por ponerle en el Criador dellas, a Él en todas amando y a todas en Él, conforme a la su santísima y divina voluntad» (Constituciones, P III, c 1, 26).

Podríamos evocar las experiencias trinitarias de santa Teresa de Jesús: «El martes después de la Ascensión... comenzó a inflamarse mi alma, pareciéndome

24. J. Clapier, La aventura mística de Isabel de la Trinidad, Monte Carmelo, Burgos 2000, 601.

25. Cf. C. García, Sor Isabel de la Trinidad, Monte Carmelo, Burgos 2006, p. 249.

26. Monumenta Historica Societatis lesu, Epp. Nad. IV, 651-652; sobre la experiencia trinitaria de san Ignacio de Loyola, cf. S. Thió de Pol, La intimidad del Peregrino, Mensajero, Bilbao 1998; sobre la experiencia trinitaria de Santa Teresa de Jesús: R. Cuartas Londoño, Experiencia trinitaria de Santa Teresa de Jesús, Monte Carmelo, Burgos 2004. 
que claramente entendía tener presente a toda la Santísima Trinidad en visión intelectual, adonde entendió mi alma por cierta manera de representación, como figura de verdad, para que lo pudiese entender mi torpeza, cómo es Dios trino y uno; y así me parecía hablarme todas tres Personas, y que se representaban dentro en mi alma distintamente, diciéndome que desde este día vería mejoría en mí en tres cosas, que cada una de estas Personas me hacían merced: la una en la caridad y en padecer con contento, en sentir una caridad con encendimiento en el alma. Entendí aquellas palabras que dice el Señor: que estarán con el alma que está en gracia las tres divinas Personas, porque las veía dentro de mí por la manera dicha... Parece quedaron en mi alma tan imprimidas aquellas tres Personas que vi, siendo un solo Dios, que a durar así imposible sería dejar de estar recogida con tan divina compañía» ( $\mathrm{R} 16$, mayo 1571).

«Esta presencia de las tres Personas que dije al principio, he traído hasta hoy -que es día de la Conmemoración de san Pablo- presentes en mi alma muy ordinario, y como yo estaba mostrada a traer sólo a Jesucristo siempre, parece que me hacía algún impedimento ver tres Personas, aunque entiendo es un solo Dios, y díjome hoy el Señor, pensando yo en esto: que erraba en imaginar las cosas del alma con la representación de las del cuerpo; que entendiese que eran muy diferentes, y que era capaz el alma para gozar mucho. Pareciome se me representó como cuando en una esponja se incorpora y embebe el agua; así me parecía mi alma que se henchía de aquella divinidad y por cierta manera gozaba en sí y tenía las tres Personas. También entendí: 'No trabajes tú de tenerme a Mí encerrado en ti, sino de encerrarte tú en Mí'. Parecíame que de dentro de mi alma - que estaban y vía yo estas tres Personas- se comunicaban a todo lo criado, no haciendo falta ni faltando de estar conmigo» ( $R 18,30$ junio 1571).

«Lo que a mí me representó, son tres Personas distintas, que cada una se puede mirar y hablar por sí. Y después he pensado que sólo el Hijo tomó carne humana, por donde se ve esta verdad. Estas Personas se aman y comunican y se conocen. Pues si cada una es por sí, ¿cómo decimos que todas tres son una esencia, y lo creemos, y es muy gran verdad y por ella moriría yo mil muertes? En todas tres Personas no hay más de un querer y un poder y un señorío, de manera que ninguna cosa pueda una sin otra, sino que de cuantas criaturas hay es sólo un Criador. ¿Podría el Hijo criar una hormiga sin el Padre? No, que es todo un poder, y lo mismo el Espíritu Santo; así que es un solo Dios todopoderoso, y todas tres Personas una Majestad. ¿Podría uno amar al Padre sin querer al Hijo y al Espíritu Santo? No, sino quien contentare a la una de estas tres Personas divinas, contenta a todas tres, y quien la ofendiere, lo mismo. ¿Podrá el Padre estar sin el Hijo y sin el Espíritu Santo? No, porque es una esencia, y adonde está el uno están todas tres, que no se pueden dividir. ¿Pues cómo vemos que están divisos tres Personas, y cómo tomó carne humana el Hijo y no el Padre ni el Espíritu Santo? Esto no lo entendí yo; los teólogos lo saben» (R 33, hacia 1572). 
La acción como tal no daña a la vida cristiana, sino la falta de amor. Se pueden ejercer brillantes carismas y espectaculares tareas de servicio al prójimo, pero sin verdadero amor o sin verdadera humildad (cf. 1 Cor 13, 1-7, cf. comentarios en Biblia de Jerusalén).

Podemos encontrar a Dios en medio de nuestras ocupaciones cotidianas y en las situaciones más diversas. Pero es preciso buscarlo.

Una seglar cristiana, Madeleine Delbrêl (1904-1964), nos ofrece el siguiente testimonio:

Empieza un día más. Jesús quiere vivirlo en mí. No está encerrado. Ha caminado entre los hombres. Conmigo está entre los hombres de hoy.

Va a encontrarse con cada uno de los que entren en casa, con cada uno de los que cruzaré por la calle, otros ricos distintos de los de su tiempo, otros pobres, otros sabios y otros ignorantes, otros niños y otros ancianos, otros santos y otros pecadores, otros sanos y otros inválidos.

Todos serán los que él ha venido a buscar.

Cada uno, el que ha venido a salvar.

A quienes me habla, él tendrá algo que responder. A quienes tengan carencias, él tendrá algo que dar. Cada uno existirá para él como si fuera el único. Tendrá que vivir su silencio en el ruido. Impulsará su paz en el tumulto. Jesús no ha cesado de ser en todo el Hijo. Quiere seguir en mí unido al Padre... Dulcemente unido en cada segundo... Jesús no ha dejado de ser enviado a todas partes. Nosotros no podemos dejar de ser en cada instante los enviados de Dios al mundo. Jesús no deja de ser enviado en nosotros, a lo largo de este día que comienza, a toda la humanidad de nuestro tiempo, de todos los tiempos, de mi ciudad y del mundo entero ${ }^{27}$.

27. M. Delbrêl, La alegría de creer, Sal Terrae, Santander 1997, 140-141. 